\title{
GRID CoMPUTING: STRATEgIC DECISION MAKING IN RESOURCE SELECTION
}

\author{
Shahriar Mohammadi ${ }^{1}$, Sajad Homayoun ${ }^{2}$, Ebrahim Torki Zadeh ${ }^{3}$ \\ ${ }^{1}$ Associate Professor, IT Group, Department of Industrial Engineering, K. N. Toosi \\ University of Technology, Tehran, Iran \\ mohammadi@kntu.ac.ir \\ ${ }^{2}$ Corresponding Author, IT Group, Department of Industrial Engineering, K. N. Toosi \\ University of Technology, Tehran, Iran \\ sajadhomayoun@gmail.com \\ ${ }^{3}$ IT Group, Department of Industrial Engineering, K. N. Toosi University of Technology, \\ Tehran, Iran and Ahvaz Research Group, National Iranian Oil Products Distribution \\ Company (NIOPDC), Ahvaz, Iran \\ e.torkizadeh@gmail.com
}

\begin{abstract}
The rapid development of computer networks around the world generated new areas especially in computer instruction processing. In grid computing, instruction processing is performed by external processors available to the system. An important topic in this area is task scheduling to available external resources. However, we do not deal with this topic here. In this paper we intend to work on strategic decision making on selecting the best alternative resources for processing instructions with respect to criteria in special conditions. Where the criteria might be security, political, technical, cost, etc. Grid computing should be determined with respect to the processing objectives of instructions of a program. This paper seeks a way through combining Analytic Hierarchy Process (AHP) and Technique for Order of Preference by Similarity to Ideal Solution (TOPSIS) to help us in ranking and selecting available resources according to considerable criteria in allocating instructions to resources. Therefore, our findings will help technical managers of organizations in choosing as well as ranking candidate alternatives for processing program instructions.
\end{abstract}

\section{KEYWORDS}

Grid Computing, Resource Selection, Strategic Decision Making, AHP, TOPSIS.

\section{INTRODUCTION}

A. What is Grid Computing?

In general, grid is aimed at sharing resources in a dynamic and probably heterogeneous environment. These resources would be accessible through a number of policies. This sharing is mainly used for computational objectives in scientific applications. They can be in forms such as $\mathrm{CPU}$, hard disk, software, as well as sensors. If your paper is intended for a conference, please contact your conference editor concerning acceptable word processor formats for your particular conference. 
In late 1990, computational grid networks emerged as substitute for current super computers to solve special problems, and they required numerous numerical computations and more amount of distributed data.

According to [1], grid computing is hardware and software infrastructure which offer a cheap, distributable, coordinated and reliable access to powerful computational capabilities.

"When the network is as fast as the computer's internal links, the machine disintegrates across the net into a set of special purpose appliances [2]".

\section{B. What is the problem?}

Usually a number of criteria affect the selection and due to the variety of criteria, decision maker would be hesitant to decide on a specific problem. The problem here is choosing an objective for processing instructions with respect to special criteria considered by an organization. They range from political, security, processing speed, place of objective, etc. (if the case is considered from another point of view, the problem of not choosing inappropriate alternatives would be the case too). The important point is that the best decision is made in the most complex situations.

Suppose we plan to construct refineries in a country. To find location, we should extended processing by relevant software. Here, we encounter two choices: First, we may go along with processing with our own facilities and wait for months or even years to arrive at the results! Or we may rely on grid computing. If the latter is selected, we should decide that taking security, political, cost and other criteria into account, which nodes are more appropriate for processing our instructions with no risk. Each criterion has its own importance, and this importance varies in different organizations. For example, in our example the criterion of security is more important than the cost criterion. The question is that "is it possible to process by any external system?" Considering malicious intents for any country or organization, the answer to this would be definitely "No" (see Figure. 1).

Figure 1. What the problem is

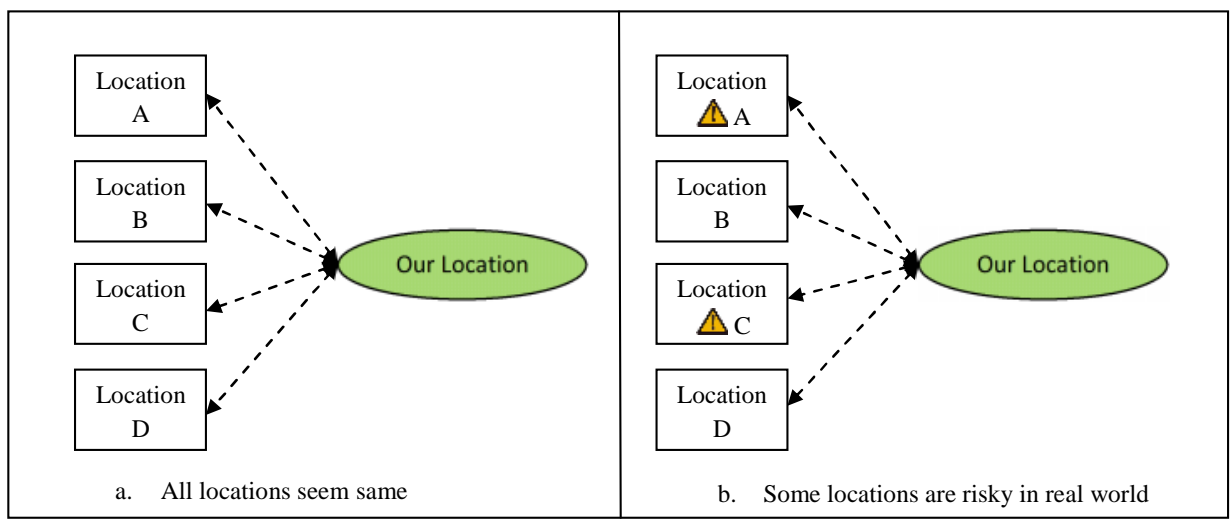

Related works are mentioned in section 2. section 3 outlines AHP method and section 4 is about TOPSIS method. The proposed framework will be dealt with in section 5. And finally Section 6 is devoted to conclusion.

\section{RELATED WORKS}

Most of authors have worked on grid computing issues form the technical perspective. Authors like Bawa and Sharma [3], Vijaykumar and Banu [4] and Metke and Ekl [5] have proposed 
International Journal of Computer Science, Engineering and Applications (IJCSEA) Vol.2, No.6, December 2012

models to make high the security of system by self-protection capability. Kavitha and Sankaranarayanan [6] have proposed a computational grid architecture for sharing of resources based on user QoS and trust, but their considered criteria are not flexible and users can not add their desired criteria to the framework.

An important issue is most of authors worked on criteria like security, etc. from the technical perspective and we are going to work on grid resource selection from the managers view. Our framework tries to help the managers when they want to block insecure resources from the list or add one according to their organization strategies and policies. We are going to design a flexible framework to rank resources.

\section{AHP}

Analytical hierarchical process (AHP) is an MADM method used for decision making and selecting an alternative out of many alternatives based on the related [7,8]. This method is created in 1980 by Saaty [5]. The Analytical Hierarchical Process reflects natural behaviour and thought of human being. This technique analyzes complicated issues based on their mutual interaction and changes them into simple form and then starts solving them.

AHP follows the following steps:

\section{- $\quad$ Step 1. Modelling AHP Structure}

In this step, the objectives of decision making are ordered as a hierarchy of decision elements which are related to each other [10]. The elements include criteria and decision alternatives (Figure 2).

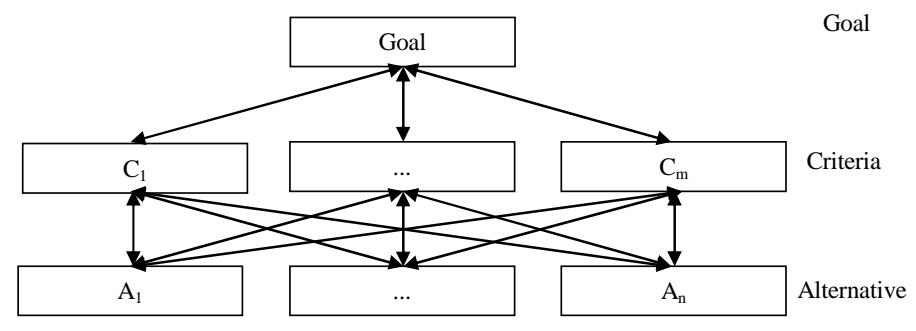

Figure. 2. AHP structure

Step 2. Establish a pair-wise comparison decision matrix

According to each criterion, a comparison is made between various alternatives. A judgment is also made on the importance of decision criterion with respect to pair-wise comparisons.

In AHP, elements in each level are compared with their related elements in higher level in pairwise and their weight is calculated. These weights are called mean weight. These weights are combined to arrive at the ultimate weight for each alternative [10].

First, there is $\mathrm{n} \times \mathrm{n}$ matrix ( $\mathrm{n}$ represents the number of criteria) and manager determines relative importance of criteria. Then, the decision matrix will be $\mathrm{n} \times \mathrm{n}$ matrix where again $\mathrm{n}$ represents the number of criteria. 
Standard Preference table (Table 1) shows how to put the selected numbers. The quantities are assigned in the matrix based on Eq. 2 .

$$
\begin{gathered}
\backslash A=\left[\begin{array}{ccc}
a_{11} & \cdots & a_{1 n} \\
\vdots & \ddots & \vdots \\
a_{n 1} & \cdots & a_{n n}
\end{array}\right] \\
a_{i j}=\frac{1}{a_{j i}}, a_{i i}=1, a_{i j}>
\end{gathered}
$$

Table 1. Standard preference table

\begin{tabular}{|c|l|}
\hline Definition & Value \\
\hline Equal importance & 1 \\
\hline Weak importance & 3 \\
\hline Essential importance & 5 \\
\hline Demonstrated importance & 7 \\
\hline Extreme importance & 9 \\
\hline Intermediate values & $2,4,6,8$ \\
\hline
\end{tabular}

- $\quad$ Step 3. Calculation of Criteria Weight

The weight of each criterion is calculated through normalization of each line or column of matrix A. There are a number of methods for calculating the matrix' weight such as Least squares method, Logarithmic least squares method, Eigenvector method, Approximation method, to name a few.

$A W=\lambda_{\max } W$

The $\lambda_{\max }$ can be acquired. If the $\lambda_{\max }$ is equal to $\mathrm{n}$ and the rank of matrix $\mathrm{A}$ is $\mathrm{n}, \mathrm{A}$ is consistent. In this case, the relative criteria can be discussed. The weight of each criterion will be calculated by normalizing any of the rows or columns of matrix A [11].

\section{- $\quad$ Step 4. Test Consistency}

AHP matrixes should be compatible. In other words, if from the manager's viewpoint, the comparative quantity of Criterion $\mathrm{C} 1$ compared with $\mathrm{C} 2$ and $\mathrm{C} 3$ is respectively 5 and 7 , then $\mathrm{C} 2$ compared with $\mathrm{C} 3$ should be higher, i.e. it should be 3 . Here two parameters are involved: consistency index (CI), and consistency ratio (CR) that are defined as below:

$C I=\frac{\lambda_{\max }-n}{n-1}$,

$C R=\frac{C I}{R I}$,

where RI is random index. For different count of criteria, it has different value demonstrated in Table 2. If $\mathrm{CR}$ is less than 0.10 , the result can be acceptable and matrix $\mathrm{A}$ is sufficient consistency. Otherwise, we have to return to step 1 and repeat again. 
International Journal of Computer Science, Engineering and Applications (IJCSEA) Vol.2, No.6, December 2012

Table 2. The relationship between value and count of criterion

\begin{tabular}{|c|c|c|c|c|c|c|c|c|c|}
\hline $\mathrm{n}$ & 1 & 2 & 3 & 4 & 5 & 6 & 7 & 8 & 9 \\
\hline $\mathrm{RI}$ & 0 & 0 & 0.58 & 0.90 & 1.12 & 1.24 & 1.32 & 1.41 & 1.45 \\
\hline
\end{tabular}

\section{TOPSIS}

In 1981, TOPSIS model was proposed by Hwang and Yoon [12] for ranking. Based on this theory, the best alternative bears two features: it is the nearest one to the positive-ideal, and it is the farthest on to the negative-ideal [13].

The positive-ideal solution minimizes the cost criteria and maximizes the benefit criteria. It is consisted of all best values attainable from the criteria. At the same time, the negative-ideal solution is a solution that maximizes the cost criteria and minimizes the benefit criteria, which has all worst values attainable from the criteria $[14,15]$.

The TOPSIS steps are followed [16].

\section{- Step 1. Constructing a decision matrix}

If the number of criteria and alternatives are $\mathrm{n}$ and $\mathrm{m}$ respectively, there will be a decision matrix with $\mathrm{m}$ lines and $\mathrm{n}$ columns. See Table 3.

Table 3. Decision Matrix

\begin{tabular}{|c|c|c|c|}
\hline & Criterion 1 & $\boldsymbol{\cdots}$ & Criterion n \\
\hline Alternative 1 & $f_{11}$ & $\cdots$ & $f_{1 \mathrm{n}}$ \\
\hline$\ldots$ & $\ldots$ & $\cdots$ & $\ldots$ \\
\hline Alternative m & $f_{m 1}$ & $\cdots$ & $f_{m n}$ \\
\hline
\end{tabular}

In Table 3, there are quantities which represents efficiency rate of each alternative with respect to the related criterion.

- Step 2. Calculation of normalized decision matrix

The normalized quantities are calculated as below.

$r_{i j}=\frac{f_{i j}}{\sqrt{\sum_{j=1}^{n} f^{2} i j}} i=1,2, \ldots, m ; j=1,2, \ldots, n$

- Step 3. Calculate the weighted normalized decision matrix

The matrix is from multiplying the normalized decision matrix by its associated weights as:

$$
v_{i j}=w_{j} \times r_{i j}, i=1,2, \ldots, m ; j=1,2, \ldots, n,
$$

where $\mathrm{w}_{\mathrm{j}}$ is the weight of the $j^{\text {th }}$ attribute or criterion, and $\sum_{\mathrm{j}=1}^{\mathrm{n}} \mathrm{w}_{\mathrm{j}}=1$. 
International Journal of Computer Science, Engineering and Applications (IJCSEA) Vol.2, No.6, December 2012

- Step 4. Determine the positive-ideal and negative-ideal solutions

$$
\begin{aligned}
& A^{k}=\left\{v_{1}^{*}, v_{2}^{*}, \ldots, v_{n}^{*}\right\}=\left\{\left(\max _{j} v_{i j} \mid i \in I^{\prime}\right),\left(\min _{j} v_{i j} \mid i \in I^{\prime \prime}\right)\right\}, i=1,2, \ldots, m ; j=1,2, \ldots, n \\
& A^{-}=\left\{v_{1}^{-}, v_{2}^{-}, \ldots, v_{n}^{-}\right\}=\left\{\left(\min _{j} v_{i j} \mid i \in I^{\prime}\right),\left(\max _{j} v_{i j} \mid i \in I^{\prime \prime}\right)\right\}, i=1,2, \ldots, m ; j=1,2, \ldots, n
\end{aligned}
$$

where $I^{\prime}$ is associated with benefit criteria, and $I^{\prime \prime}$ is associated with cost criteria.

- Step 5. Using n-dimensional Euclidean distance

The closeness of each alternative to the positive-ideal is calculated as below:

$D_{i}^{*}=\sum_{j=1}^{n} d\left(v_{i j}, v_{j}^{*}\right) i=1,2, \ldots, m$.

Distance to the negative-ideal is also calculated as below:

$D_{i}^{-}=\sum_{j=1}^{n} d\left(v_{i j}, v_{j}^{-}\right) i=1,2, \ldots, m$.

- Step 6. Calculation of Closeness to Ideal condition

It is defined for $i^{\text {th }}$ alternative :

$C C_{i}^{*}=\frac{D_{i}^{-}}{D_{i}^{*}+D_{i}^{-}}$.

- $\quad$ Step 7. Ranking

Ranking is made based on $C C_{i}^{*}$. This quantity is between $0-1$ for each alternative. The ultimate ranking will be descending $C C_{i}^{*}$ and $C C_{i}^{*}$ will be the higher one [17].

\section{Proposed FrameWork}

The usefulness of a combined AHP and TOPSIS is well documented [18], but we use it to solve a different problem. We designed a framework and it is shown in Figure 3. Let us review our suggested framework in an example. 
International Journal of Computer Science, Engineering and Applications (IJCSEA) Vol.2, No.6, December 2012

Figure 3. Proposed model.

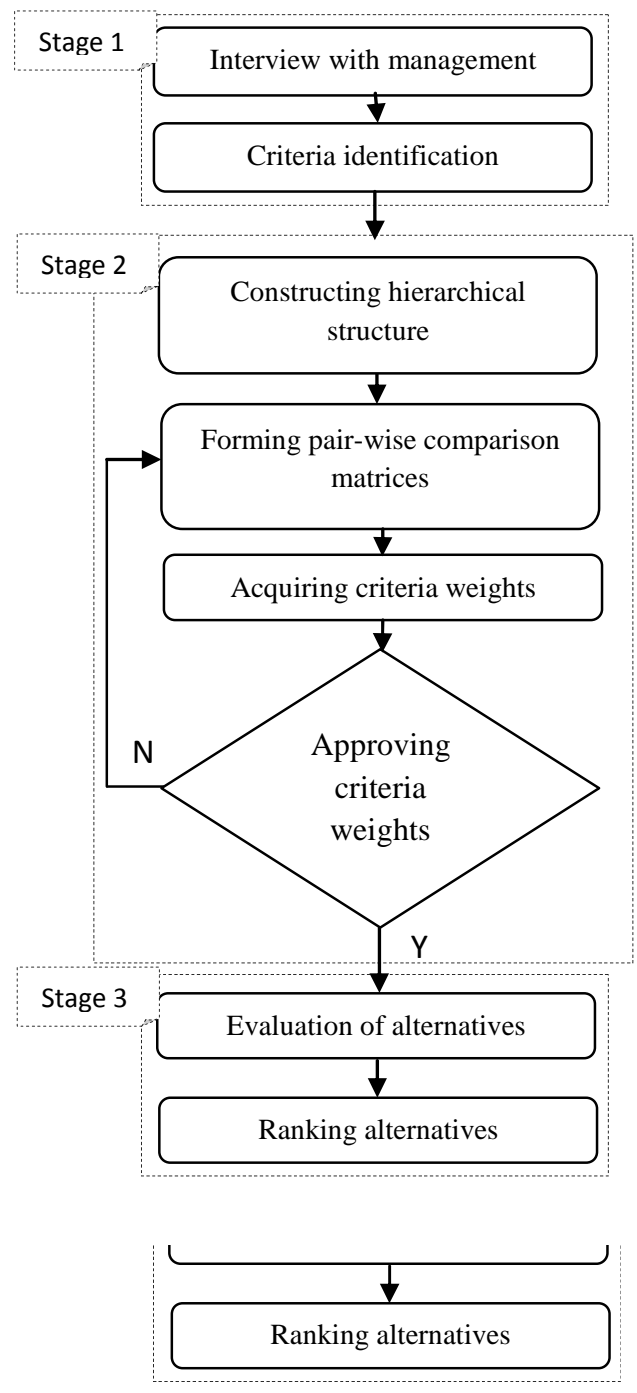

Imagine we intend to choose a processor for finding the best location for a refinery.

- Stage 1 .

In this stage, objectives and strategies of the manager will be identified, and the evaluation criteria will be selected through those objectives. The manager has determined these criteria:

1) Cost: Cost per each clock or instruction.

2) Security: confidentiality and security of executing instructions.

3) Location: country or region.

4) Process speed: execution time of each instruction

5) RTT (Round Trip Time): Time of trip and return between source and destination.

Let us we intend to select an alternative out of the alternatives: A, B, C. 
- Stage 2 .

We build the hierarchical structure of decision elements (Figure 4).

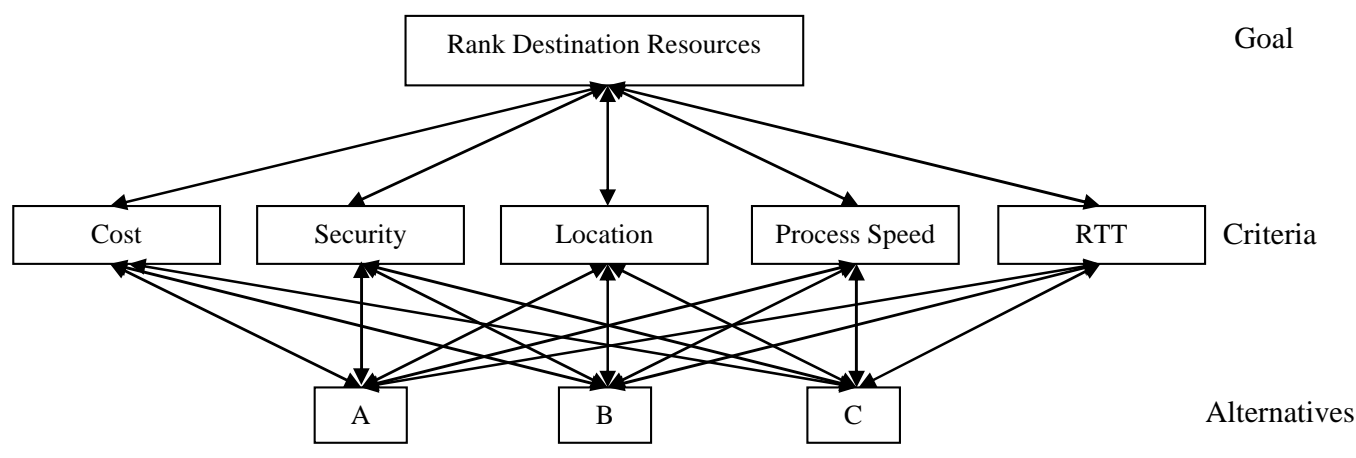

RTT: Round Trip Time

Figure 4. Hierarchical evaluation structure and criteria weight of $\mathrm{Z}$ site

We introduce pair-comparison matrix for five criteria and ask the manager to put weight based on priorities (Table 4$)$.

Table 4. Priorities of criteria

\begin{tabular}{|c|c|c|c|c|c|}
\hline Criteria & Cost & Security & Location & $\begin{array}{c}\text { Process } \\
\text { Speed }\end{array}$ & RTT \\
\hline Cost & $\mathbf{1}$ & $1 / 9$ & $1 / 3$ & $1 / 3$ & 1 \\
\hline Security & 9 & $\mathbf{1}$ & 7 & 9 & 9 \\
\hline Location & 3 & $1 / 7$ & $\mathbf{1}$ & 3 & 7 \\
\hline $\begin{array}{c}\text { Process } \\
\text { Speed }\end{array}$ & 3 & $1 / 9$ & $1 / 3$ & $\mathbf{1}$ & 3 \\
\hline RTT & 1 & $1 / 9$ & $1 / 7$ & $1 / 3$ & $\mathbf{1}$ \\
\hline \begin{tabular}{c} 
Incon.= 0.08 \\
\hline
\end{tabular} & & & & & \\
\hline
\end{tabular}

We build matrix for each criterion, and determine alternatives' status towards each other (Table 5, Table 6, Table 7, Table 8, Table 9).

Table 5. Security criteria pair-wise comparison

\begin{tabular}{|c|c|c|c|}
\hline Security & $\mathbf{A}$ & $\mathbf{B}$ & $\mathbf{C}$ \\
\hline $\mathbf{A}$ & 1 & $1 / 7$ & $1 / 3$ \\
\hline $\mathbf{B}$ & & 1 & 3 \\
\hline $\mathbf{C}$ & & & 1 \\
\hline Incon. $\mathbf{= 0 . 0 1}$ & & & \\
\hline
\end{tabular}


International Journal of Computer Science, Engineering and Applications (IJCSEA) Vol.2, No.6, December 2012

Table 6. Cost criteria pair-wise comparison

\begin{tabular}{|c|c|c|c|}
\hline Cost & A & B & C \\
\hline A & 1 & 3 & 7 \\
\hline B & & 1 & 5 \\
\hline C & & & 1 \\
\hline Incon $=\mathbf{0 . 0 6}$ & & & \\
\hline
\end{tabular}

Table 7. Location criteria pair-wise comparison

\begin{tabular}{|c|c|c|c|}
\hline Location & A & B & C \\
\hline Location & A & B & C \\
\hline A & 1 & 3 & 3 \\
\hline B & & 1 & $1 / 3$ \\
\hline C & & & 1 \\
\hline Incon=0.13 & & & \\
\hline
\end{tabular}

Table 8. Process speed criteria pair-wise comparison

Table 9. Process speed criteria pair-wise comparison

Then we calculate the weight of matrixes. For example, we used Expert Choice software

\begin{tabular}{|c|c|c|c|}
\hline Location & A & B & C \\
\hline A & 1 & 5 & 7 \\
\hline B & & 1 & 3 \\
\hline C & & & 1 \\
\hline Incon=0.06 & & & \\
\hline
\end{tabular}

\begin{tabular}{|c|c|c|}
\hline Level 1 & Alts & Prty \\
\hline \multirow[t]{2}{*}{ Percent Cost $[L=-046]$} & & 4.7 \\
\hline & A & .031 \\
\hline \multirow{2}{*}{ Cost [L: .046] } & B & .013 \\
\hline & C & .003 \\
\hline \multirow{2}{*}{ Percent Process Speed [L: .089] } & & 10.3 \\
\hline & $\mathrm{A}$ & .060 \\
\hline \multirow[t]{2}{*}{ Process Speed (L: .089) } & B & .014 \\
\hline & C & .029 \\
\hline \multirow[t]{2}{*}{ Percent Security [L: .647] } & & 64.9 \\
\hline & $\mathrm{A}$ & .057 \\
\hline \multirow{2}{*}{ Security (L: .647) } & B & .435 \\
\hline & C & .158 \\
\hline \multirow[t]{2}{*}{ Percent Location [L: . 178] } & & 16.4 \\
\hline & A & .031 \\
\hline \multirow{2}{*}{ Location (L: .178) } & B & .120 \\
\hline & C & .013 \\
\hline \multirow[t]{2}{*}{ Percent RTT [L: .040] } & & 3.7 \\
\hline & A & .027 \\
\hline \multirow[t]{2}{*}{ RTT (L: .040) } & B & .007 \\
\hline & C & .003 \\
\hline
\end{tabular}

version 11, and arrived at Figure 5

Figure 5. Ultimate Weight calculated by Expert Choice 11. 
International Journal of Computer Science, Engineering and Applications (IJCSEA) Vol.2, No.6, December 2012

- $\quad$ Stage 3.

Once stages 1 and 2 are finished, we arrived at weights of each criterion and alternative. In this stage, we evaluated alternatives and ultimate ranking. Table 10 and Table 11 is formed by AHP and it is used as input for TOPSIS model. Then it is normalized. The TOPSIS model gave us Table 13 as final results according to Table 12 .

Table 10. Calculated weights by AHP

\begin{tabular}{|c|c|c|c|c|c|}
\hline Criteria & Cost & Security & Location & $\begin{array}{c}\text { Process } \\
\text { Speed }\end{array}$ & RTT \\
\hline A & 0.649 & 0.088 & 0.188 & 0.584 & 0.731 \\
\hline B & 0.279 & 0.669 & 0.731 & 0.135 & 0.188 \\
\hline C & 0.072 & 0.243 & 0.081 & 0.281 & 0.081 \\
\hline
\end{tabular}

Table 11. Ultimate weight for criteria by AHP

\begin{tabular}{|c|c|}
\hline Criteria & Weight \\
\hline Cost & 0.046 \\
\hline Security & 0.647 \\
\hline Location & 0.178 \\
\hline Process Speed & 0.089 \\
\hline RTT & 0.040 \\
\hline
\end{tabular}

Table 12. Status for each alternative

\begin{tabular}{|c|l|l|l|l|l|}
\hline Criteria & Cost & \multicolumn{1}{|c|}{ Security } & Location & $\begin{array}{c}\text { Process } \\
\text { Speed }\end{array}$ & RTT \\
\hline A & 0.0298 & 0.0569 & 0.0334 & 0.0519 & 0.0292 \\
\hline B & 0.0128 & 0.4328 & 0.1301 & 0.0120 & 0.0075 \\
\hline C & 0.0033 & 0.1572 & 0.0144 & 0.0250 & 0.0032 \\
\hline
\end{tabular}

Table 13. Positive-Ideal and Negative-Ideal distance for each alternative

\begin{tabular}{|c|c|c|}
\hline & $*$ & - \\
\hline $\mathbf{A}$ & 0.1506 & 0.0033 \\
\hline $\mathbf{B}$ & 0.0023 & 0.1547 \\
\hline $\mathbf{C}$ & 0.0913 & 0.0101 \\
\hline
\end{tabular}

The final weight is calculated by Eq. 12 and is showed in Table 14 . 
International Journal of Computer Science, Engineering and Applications (IJCSEA) Vol.2, No.6, December 2012

Table 14. Final weights from TOPSIS

\begin{tabular}{|c|c|}
\hline & Final weight \\
\hline A & 0.1539 \\
\hline B & 0.1570 \\
\hline C & 0.1014 \\
\hline
\end{tabular}

Now the ultimate ranking reflects descending order of alternatives' weights, where in our example they are A, C, and B.

We reserve the alternatives with the second rank, or we may divide the program into parts and use the resources in parallel.

\section{CONCLuSions}

Grid computing helps us to process computer instructions faster and it is very useful in processing programs with huge amount of instructions. Sometimes we have to avoid deputing instructions to potential inappropriate available resources for the reasons such as cost, security, governmental policies, etc. In this article, a method is proposed for decision making and choosing one or some resources out of existing alternatives with respect to the special conditions of an organization. This method helps decision makers (managers) in complicated conditions where a number of criteria such as security, cost, processing speed, etc. are involved in choosing an alternative. We developed a framework based on AHP and TOPSIS and described it through an example. AHP is used to put weight to criteria and alternatives. We assigned its output as input to TOPSIS and finally we arrived at the ultimate ranking leading to an optimum choice.

\section{REFERENCES}

[1] Foster, I. (2002), "What is the Grid", Daily News and Information for the Global Grid Community J., Vol. 1, No. 6.

[2] Barroso \& Jose Morales (2005), "From Computer Networks to the Computer on Net, the Convergence of Internet, Broadband and Telephone Networks in the IEEE 802 Standards," IEEE Global Communication Newsletter, page 2.

[3] Kumar, R., Bawa \& Sharma, G. (2012), "Reliable Resource Selection in Grid Environment". In International Journal of Grid Computing and Applications, Vol. 3, No. 1.

[4] Vijayakumar, V. \& Banu, R.S.D.W. (2009), "Secured Resource Selection in Grid Computing: Trust and Reputation Sentient Scheme", Advances in Communication and Networking, Vol. 27, pp. 169183.

[5] Metke, A.R. \& Ekl, R.L. (2010), "Security Technology for Smart Grid Networks", Smart Grid, IEEE Transactions on , Vol. 1, No. 1, pp. 99-107.

[6] G.Kavitha \& V.Sankaranarayanan. (2011), "Resource Selection in Computational Grid Based on User QoS and Trust", IJCSNS International Journal of Computer Science and Network Security, Vol. 11, No. 3, pp. 214-221.

[7] Gumus, A. T. (2009), "Evaluation of hazardous waste transportation firms by using a two-step fuzzyAHP and TOPSIS methodology," Expert Systems with Applications J., Vol. 36, pp. 4067-4074.

[8] Lin, M. C., Wang, C. C., Chen, M. S., \& Chang, C. A. (2008), "Using AHP and TOPSIS approaches in customer-driven product design process," Computers in Industry J., Vol. 59, No. 1, pp. 17-31.

[9] Saaty, T. L. (1980), "The analytic hierarchy process," New York: McGraw-Hill.

[10] Albayrak, E., \& Erensal, Y. C. (2004), "Using analytic hierarchy process (AHP) to improve human performance. An application of multiple criteria decision making problem," Intelligent Manufacturing J., Vol. 15, pp. 491-503. 
International Journal of Computer Science, Engineering and Applications (IJCSEA) Vol.2, No.6, December 2012

[11] Wang, J. J., \& Yang, D. L. (2007), "Using a hybrid multi-criteria decision aid method for information systems outsourcing," Computers \& Operation Research J., Vol. 34, pp. 3691-3700.

[12] Hwang, C. L., \& Yoon, K. (1981), "Multiple attribute decision making: Methods and applications. A state of the art survey", New York: Springer-Verlag.

[13] Ertugrul, I., \& Karakasoglu, N. (2007), "Performance evaluation of Turkish cement firms with fuzzy analytic hierarchy process and TOPSIS methods," Expert Systems with Applications J., Vol. 36, No. 1, pp. 702-715.

[14] Wang, Y. J. (2008), "Applying FMCDM to evaluate financial performance of domestic airlines in Taiwan,” Expert Systems with Applications J., Vol. 34, pp. 1837-1845.

[15] Wang, Y. M., \& Elhag, T. M. S. (2006), "Fuzzy TOPSIS method based on alpha level sets with an application to bridge risk assessment," Expert Systems with Applications J., vol. 31, pp. 309-319.

[16] Shyur, H. J., \& Shih, H. S. (2006), "A hybrid MCDM model for strategic vendor selection," Mathematical and Computer Modeling J., Vol. 44, pp. 749-761.

[17] Opricovic, S., \& Tzeng, G. H. (2007), "Extended VIKOR method in comparison with outranking methods," Operational Research Euro. J., Vol. 178, No. 2, pp. 514-529.

[18] Xiaobing Yu, Shunsheng Guo, Jun Guo \& Xiaorong Huang (2011), "Rank B2C e-commerce websites in e-alliance based on AHP and fuzzy TOPSIS", Expert Systems with Applications J., Vol. 38, pp. 3550-3557. 